\title{
BMJ Open Risk factors for non-communicable diseases in Bangladesh: findings of the population-based cross-sectional national survey 2018
}

\author{
Baizid Khoorshid Riaz, ${ }^{1}$ Md Ziaul Islam (1) ,2 A N M Shamsul Islam, ${ }^{1}$ \\ M M Zaman (1) , ${ }^{3}$ Md Akram Hossain,, ${ }^{4}$ Md Mujibur Rahman, ${ }^{5}$ Fahmida Khanam, ${ }^{1}$ \\ K M Bayzid Amin, ${ }^{1}$ Irfan Nowroze Noor ${ }^{1}$
}

To cite: Riaz BK, Islam MZ, Islam ANMS, et al. Risk factors for non-communicable diseases in Bangladesh: findings of the populationbased cross-sectional national survey 2018. BMJ Open 2020;10:e041334. doi:10.1136/ bmjopen-2020-041334

- Prepublication history and additional materials this paper is available online. To view these files, please visit the journal online (http://dx.doi.org/10. 1136/bmjopen-2020-041334).

Received 08 June 2020 Revised 21 0ctober 2020 Accepted 22 October 2020

\section{Check for updates}

(c) Author(s) (or their employer(s)) 2020. Re-use permitted under CC BY-NC. No commercial re-use. See rights and permissions. Published by BMJ.

${ }^{1}$ Public Health and Hospital Administration, National Institute of Preventive and Social Medicine, Dhaka, Bangladesh ${ }^{2}$ Community Medicine, National Institute of Preventive and Social Medicine, Dhaka, Bangladesh ${ }^{3}$ Country Office, Bangladesh, WHO Regional Office for SouthEast Asia, Dhaka, Bangladesh ${ }^{4}$ Microbiology, National Institute of Preventive and Social Medicine, Dhaka, Bangladesh ${ }^{5}$ Medicine, Dhaka Medical College and Hospital, Dhaka, Bangladesh

Correspondence to Professor Md Ziaul Islam; dr.ziaul.islam@gmail.com

\section{ABSTRACT}

Objectives To determine the national prevalence of risk factors of non-communicable diseases (NCD) in the adult population of Bangladesh.

Design The study was a population-based national crosssectional study.

Setting This study used 496 primary sampling units (PSUs) developed by the Bangladesh Bureau of Statistics. The PSUs were equally allocated to each division and urban and rural stratum within each division.

Participants The participants were adults aged 18 to 69 years, who were usual residents of the households for at least 6 months and stayed the night before the survey. Out of 9900 participants, 8185 (82.7\%) completed STEP-1 and STEP-2, and 7208 took part in STEP-3.

Primary and secondary outcome The prevalence of behavioural, physical and biochemical risk factors of NCD. Data were weighted to generate national estimates. Results Tobacco use was significantly $(p<0.05)$ higher in the rural $(45.2 \%)$ than the urban $(38.8 \%)$ population. Inadequate fruit/vegetable intake was significantly $(p<0.05)$ higher in the urban $(92.1 \%)$ than in the rural (88.9\%) population. The mean salt intake per day was higher in the rural $(9.0 \mathrm{~g})$ than urban $(8.9 \mathrm{~g})$ population. Among all, $3.0 \%$ had no, $70.9 \%$ had 1 to 2 and $26.2 \%$ had $\geq 3$ NCD risk factors. The urban population was more likely to have insufficient physical activity (adjusted OR (AOR): $1.2,95 \% \mathrm{Cl}: 1.2$ to 1.2 ), obesity (AOR: $1.5,95 \% \mathrm{Cl}: 1.5$ to 1.5), hypertension (AOR: 1.3, 95\% Cl: 1.3 to 1.3 ), diabetes (AOR: $1.6,95 \% \mathrm{Cl}: 1.6$ to 1.6) and hyperglycaemia (AOR: $1.1,95 \% \mathrm{Cl}: 1.1$ to 1.1$)$.

Conclusions Considering the high prevalence of the behavioural, physical and biochemical risk factors, diverse population and high-risk group targeted interventions are essential to combat the rising burden of NCDs.

\section{INTRODUCTION}

Non-communicable diseases (NCDs) are the result of a combination of genetic, sociodemographic, physical, biochemical and behavioural factors. The global report on death by cause shows that more than $65 \%$ of 56 million global deaths were due to NCDs. ${ }^{1}$
Strengths and limitations of this study

- The survey covered the entire country for the first time to estimate the prevalence of noncommunicable diseases (NCD) risk factors comprising all the three steps of the WHO STEPS approach.

- Rigorous methodology and cross-matching the data with their physical and biochemical parameters helped us to generate country representative data by controlling bias.

- Comprehensive findings on behavioural, physical and biochemical risk factors could be used to devise diverse intervention programmes to reduce the rising burden of NCD.

- As a cross-sectional study, limits its ability to infer causal relationships among the risk factors.

- Behavioural data may have little bias as the participants of this self-report survey may tend to report in socially desirable ways.

Three-fourths of this global mortality due to NCDs occur in low- and middle-income countries. ${ }^{2}$ Each year premature deaths affect equally both men and women ( 15 million each) due to NCDs. ${ }^{3}$ Four major NCDs; cardiovascular disease, cancer, diabetes and respiratory diseases are responsible for $82 \%$ of NCD mortality. ${ }^{4}$

Demographic transition and rapid urbanisation have led to changes in lifestyles; food and tobacco consumption continues to experience high morbidity and mortality from NCDs. The rise in NCDs largely stems from four behavioural risk factors: tobacco use, unhealthy diet, insufficient physical activity and the harmful use of tobacco and alcohol. ${ }^{5}$ Lifestyle change in an individual following the trend of globalisation, supermarket growth, rapid urbanisation and sedentary lifestyles invites these risk factors around him. ${ }^{6}$ 
In the Bangladeshi adult population, NCD risk factors are found to exist in clusters that become more prominent with the increasing age of that individual. ${ }^{7}$ Bangladesh is passing through a demographic transition and an epidemiological transition and currently has a double burden of diseases. ${ }^{8}$ NCDs account for $67 \%$ of total deaths in Bangladesh. ${ }^{9}$ Diverse epidemiological studies have identified risk factors including unhealthy food consumption, tobacco use, insufficient physical inactivity, high body mass index (BMI), raised blood pressure, unfavourable blood lipid and raised blood glucose level. ${ }^{10}$ Tobacco consumption is the leading risk factor for major NCDs in Bangladesh. ${ }^{11}$ The first STEPS survey was done in 2010, but there was a lack of biochemical measurements and hence no national estimations of diabetes and dyslipidaemia prevalence existed. There is limited evidence on certain risk factors that exist in Bangladesh at the national level. ${ }^{12}$ This second nationwide STEPS survey along with biochemical measurement for blood glucose, lipid profile and urinary sodium helped to provide the first comprehensive estimates of NCD risk factors in the country.

Member states of WHO have agreed 25 indicators across three areas that focus on the key outcomes, risk factors and national systems response needed to prevent and control NCDs. One mortality target, six risk factor targets and two national systems targets are considered..$^{13}$ As a member state, Bangladesh intends to estimate the prevalence of NCD risk factors in the adult people of the country. STEPwise approach is a WHO-developed, standardised framework for monitoring the magnitude of NCD risk factors comprising three steps; STEP-1 determines behavioural risk factors; STEP-2 determines physical risk factors and STEP-3 finds out biological risk factors. The STEPS survey 2018 for NCD risk factors in Bangladesh was carried out to determine the national prevalence of NCDs risk factors in the adult population of Bangladesh.

\section{METHODS}

\section{Study design and setting}

The STEPS survey 2018 was a countrywide populationbased cross-sectional study conducted from September 2017 to June 2018. The samples were collected by multistage, geographically stratified probability-based sampling using the primary sampling units (PSUs) developed by the Bangladesh Bureau of Statistics (BBS) for the census.

\section{Study population}

The study population included adults aged 18 to 69 years, the usual residents of the household for at least 6 months and were present there the night before the survey. We excluded those people who primarily resided in a military base or group quarters, hospitals, prisons, nursing homes and other institutions or those too frail and mentally or physically unfit to participate in the study or those unable or unwilling to participate in the study.

\section{Sample size}

To ensure generalisation and reliability of the study results to the entire target population in Bangladesh, the
WHO recommended sample size calculator (sample size calculator STEPS) was used to derive a sample size. The calculated sample size was sufficient to produce reliable estimates for all the indicators for men and women and four age-groups (18 to 24,25 to 39,40 to 54 and 55 to 69 ). The prevalence of NCD risk factors, relative precision rate $(20 \%)$ and the feasibility of the survey were considered to calculate the sample size. Based on the prevalence of obesity, 472 people were required for effective analysis for each group. Considering the person non-response rate $(10 \%)$ and household non-coverage rate $(10 \%)$ shared by the previous surveys of Bangladesh Demographic Health Survey and BBS, overall, 20\% non-response rate and a design effect of 2 were used to calculate the final sample size. Initially, we considered 496 PSUs updated by BBS in 2017. During the fieldwork, we excluded one PSU due to inaccessibility. As a result, the final adjusted sample size was 9900 adults of 495 PSUs.

\section{Sampling frame}

The sampling frame was developed based on the complete list of PSUs prepared by the BBS containing information about PSU location, type of residence and the estimated number of residential households. All the PSUs were mapped for the survey and comprised of 293 533 PSUs: 65193 urban and 228340 rural PSUs. The household lists updated by BBS served as the sampling frame for the selection of households. Twenty households were randomly selected from each PSU and randomly assigned as 'male' or 'female' in a ratio that produced equal numbers of male and female households. One individual was sampled randomly from all the eligible adults in a household. No replacement or change of the preselected households was allowed at the implementing stage to prevent bias.

\section{Sampling strategy}

The PSUs were allocated equally to each division (62 each), and urban and rural stratum (248 PSUs each). The PSUs were arranged by population size in terms of household numbers for both urban and rural stratum. In each stratum, 31 PSUs were selected independently in each division by probability proportional to size sampling.

\section{Data collection}

Data were collected using a standardised pretested questionnaire developed considering WHO STEPS questionnaire (V.3.2) by incorporating all of the core questions with some selected expanded and country-specific questions. The questionnaire was translated into Bengali and validated by translation and back translation. Data collection techniques included a face-to-face interview (STEP 1), physical measurements (STEP 2) and body fluid (blood and urine) collection (STEP 3). Data were collected by an android device on the spot and transferred into the cloud through ODK software. 


\section{STEP-1 (behavioural risk factors ascertainment)}

Core items included demographic information and measures of tobacco use, fruit and vegetable, alcohol and salt consumption, physical activity, blood pressure, diabetes and total cholesterol. Data enumerators having post-graduation in sociology/psychology/anthropology conducted the interviews and physical measurements. Medical technologists having diploma/bachelor/ master's degree in medical laboratory science collected and processed the samples. The recruited staff underwent training covering all the steps with interactive sessions, skill development and pilot testing.

\section{STEP-2 (physical measurements)}

Core items included measurement of blood pressure, height, weight, hip and waist circumference. Validated instruments were used for measuring these parameters. The height and weight of the participants were measured with barefoot and light clothing. Weight was measured to the nearest $10 \mathrm{~g}$ using a digital weight measuring machine, while height was measured to the nearest $0.1 \mathrm{~cm}$ using a portable stadiometer. The tailor measuring tape was used for measuring waist and hip circumference. All the instruments were calibrated routinely during the survey. A digital blood pressure measuring machine, supplied by WHO with uniform cuff-size with automatic measurement of blood pressure and pulse, was used for measuring blood pressure.

\section{STEP-3 (biochemical measurements)}

For estimation of blood sugar and lipid profile level, each participant was advised to remain nothing per mouth (except plain water) for at least 12 hours before blood collection. Blood and urine samples were collected under strict aseptic precautions. On the first visit of STEP-3, written instructions on fasting state, and appointment date for the blood test were given to each participant and asked to visit maintaining the schedule. Initially, $5 \mathrm{~mL}$ of blood was collected by disposable syringe, and plasma and serum were separated by centrifuging within 30 min to 1 hour after collection. Followed by $2 \mathrm{~mL}$ of this blood was transferred to a fluoride-oxalate vacutainer for serum glucose testing, and $3 \mathrm{~mL}$ of the blood was kept in a normal tube and allowed to stand for the separation of plasma (for lipid profile) with proper labelling. The sample for blood glucose was left in the upright position in a vacutainer rack and then centrifuged and separated serum was kept in the cold box $\left(2^{\circ} \mathrm{C}\right.$ to $\left.8^{\circ} \mathrm{C}\right)$ surrounded by ice packs.

The participants were asked to collect $20 \mathrm{~mL}$ urine in supplied labelled screw-capped plastic urine pot in the evening before bedtime to submit to the medical technologist on the following day for blood sample collection at the prefixed place. All the collected blood and urine samples of a day were sent to the NIPSOM laboratory within 24 hours of collection. At the central laboratory, the blood and urine samples were received and sent with a laboratory ID number for testing sodium and urine.
After the estimation of blood glucose and lipid profile, the remaining serum sample was kept in Cryo vials at $-70^{\circ} \mathrm{C}$. After the estimation of urinary sodium, and the remaining urine sample was discarded.

\section{Quality control}

Quality control procedures included regular field supervision and daily review of collected data. Laboratory instruments were calibrated following the standard procedure and the findings were validated with the same sample findings of another standard national laboratory. The blood and urine samples were tested in the NIPSOM central laboratory dividing the sample into multiple samples and the same samples multiple times to compare the findings and to validate the instruments and procedure. To ensure accurate findings of the biochemical samples; pretesting was done in both urban and rural areas from where samples were sent to the NIPSOM laboratory. Accordingly, samples were received at different time intervals after collection and were tested at different times and the findings were compared.

\section{Data management}

Data were entered directly in the ODK software on the personal digital assistants (PDAs). Data were sent electronically and stored in the ONA database server. The field team uploaded data daily on the server. The stored data were downloaded into Microsoft Excel format for consistency and validity check at the central office. Each participant had a unique identifier QR-code and personal identification number, which were used for merging data of STEP-1, STEP-2 and STEP-3. Data were cleaned and analysed following WHO STEPS recommended guidelines.

\section{Statistical methods}

We weighted the data considering selection probabilities of PSU, household, sex and individuals within the household so that the study results conform to the population of Bangladesh. Calibration was done to replicate population distribution. Prevalence was estimated using the STEPS recommended cut-off values. ${ }^{14}$ Data were analysed using Stata V.15.0, and Epi Info V.3.4 was used as a reference for programming purposes and cross-validation of Stata outputs. Missing data were excluded from the analysis. Economic status was determined by the principal component analysis of the wealth index based on household assets. Descriptive statistics included percentage, and inferential statistics included logistic regression to determine the NCD risk factors. Background characteristics were cross-tabulated with NCD risk factors, and the $\mathrm{X}^{2}$ test was performed to investigate the significance of the relationships. Outcome measures and differences between groups were calculated at $95 \%$ CI and significant at $p$ value $<0.05$. To assess the degree of association of the risk factors, we used the adjusted OR (AOR). We tested multicollinearity and adjusted the risk factors through multivariable logistic regression analysis. 
We took informed consent from each participant before data collection. Confidentiality and privacy of the participants and anonymity of data were maintained strictly. We carried out all of the activities in conformity with the revised declarations of Helsinki.

\section{RESULTS}

Among the target 9900 population, 8185 (82.7\%) completed STEP-1 and STEP-2 while 7208 took part in STEP-3. Out of 7208 participants, 7056 gave the blood and 7028 urine sample. The majority of the urban participants were men $(51.5 \%)$, and the majority of the rural participants were women $(51.4 \%)$. Around $33.0 \%$ of urban and $47.0 \%$ of rural participants had no education or less than primary level education. The majority of the rural $(45.7 \%)$ and urban $(36.9 \%)$ participants were homemakers. The 'richest' comprised $28.5 \%$ urban and $12.6 \%$ rural, and the 'poorest' included $18.1 \%$ urban and $17.6 \%$ rural population (table 1 ).

Mean serving of fruits and/or vegetables per day was 2.6 (95\% CI: 2.5 to 2.7 ), and the mean duration of physical activity per day was 247.9 (95\% CI: 247.8 to 248.0 ) $\mathrm{min}$. Mean BMI was 22.7 (95\% CI: 22.5 to 22.8 ) $\mathrm{kg} / \mathrm{m}^{2}$, and mean waist circumference was 78.6 (95\% CI: 78.2 to $79.1) \mathrm{cm}$. Both mean systolic blood pressure $(122.6(95 \%$ CI: 122.0 to 123.1$) \mathrm{mm} \mathrm{Hg}$ ) and diastolic bloodpressure (80.6 (95\% CI: 80.2 to 81.0 ) $\mathrm{mm} \mathrm{Hg}$ ) was higher in urban population. Both mean fasting blood glucose (5.6 (95\% CI: 5.5 to 5.6$) \mathrm{mmol} / \mathrm{L})$ and mean total cholesterol $(4.4$ (95\% CI: 4.4 to 4.5$) \mathrm{mmol} / \mathrm{L}$ ) was higher in the richest but mean salt intake per day was $(9.1$ (95\% CI: 9.1 to $9.1) \mathrm{g}$ ) in the poor population (table 2).

The prevalence of tobacco consumption was $43.7 \%$ and was significantly $(\mathrm{p}<0.05)$ higher in men $(59.6 \%)$ and rural $(45.2 \%)$ population. The prevalence of alcohol consumption was $1.5 \%$ and was significantly $(\mathrm{p}<0.05)$ higher in men $(2.9 \%)$ and businessman $(3.2 \%)$. The prevalence of inadequate fruit and vegetable intake was $89.6 \%$ and was significantly $(\mathrm{p}<0.05)$ higher in the elderly $(92.3 \%)$ and urban $(92.1 \%)$ population. The prevalence of insufficient physical activity was $12.3 \%$ and was significantly $(\mathrm{p}<0.05)$ higher in the women $(14.8 \%)$ and urban $(14.1 \%)$ population (table 3$)$.

The prevalence of overweight and obesity was $25.9 \%$ and was significantly $(\mathrm{p}<0.05)$ higher in the women $(33.7 \%)$, urban $(34.3 \%)$ and 'richest' (34.3\%) population. The prevalence of hypertension was $21.0 \%$ and was significantly $(\mathrm{p}<0.05)$ higher in the urban $(25.2 \%)$ and 'richest' $(24.9 \%)$ population. The prevalence of diabetes was $8.3 \%$ and was significantly $(\mathrm{p}<0.05)$ higher in the urban (13.2\%), elderly (16.3\%) and 'richest' (11.9\%) population. The prevalence of hypercholesterolaemia was $28.4 \%$ and was significantly $(\mathrm{p}<0.05)$ higher in women $(29.3 \%)$ and urban $(32.4 \%)$ population (table 3 ).

The elderly (AOR: $4.5,95 \%$ CI: 4.5 to 4.5 ) and ever married (OR: $1.4,95 \%$ CI: 1.4 to 1.4 ) were more likely to have the smoking habit. The urban population was more
Table 1 Background characteristics (weighted) of the adult population of Bangladesh $(n=8185)$

\begin{tabular}{|c|c|c|c|}
\hline $\begin{array}{l}\text { Background } \\
\text { characteristics }\end{array}$ & Urban, \% & Rural, \% & Both, \% \\
\hline \multicolumn{4}{|l|}{ Age } \\
\hline $18-24$ & 23.6 & 24 & 23.9 \\
\hline $25-39$ & 42.1 & 39 & 39.7 \\
\hline $40-54$ & 19.7 & 19.7 & 19.7 \\
\hline $55-69$ & 14.6 & 17.2 & 16.6 \\
\hline \multicolumn{4}{|l|}{ Sex } \\
\hline Male & 51.5 & 48.6 & 49.3 \\
\hline Female & 48.5 & 51.4 & 50.7 \\
\hline \multicolumn{4}{|l|}{ Highest level of education } \\
\hline No education / <primary & 32.9 & 47 & 43.9 \\
\hline Primary & 27.8 & 32 & 31.1 \\
\hline Secondary & 18.6 & 10.8 & 12.6 \\
\hline More than secondary & 20.7 & 10.1 & 12.5 \\
\hline \multicolumn{4}{|l|}{ Marital status } \\
\hline Never married & 14.2 & 11.8 & 12.3 \\
\hline Currently married & 80.9 & 83.2 & 82.7 \\
\hline Ever married* & 4.8 & 5.1 & 5 \\
\hline \multicolumn{4}{|l|}{ Occupation } \\
\hline Employed & 36.7 & 35.7 & 35.9 \\
\hline Businessman & 13.3 & 10.1 & 10.9 \\
\hline Student & 8.4 & 5.4 & 6.1 \\
\hline Homemaker & 36.9 & 45.7 & 43.7 \\
\hline Unemployed & 2.3 & 2.1 & 2.1 \\
\hline Others & 2.3 & 1 & 1.3 \\
\hline \multicolumn{4}{|c|}{ Economic status (Based on Wealth Index) } \\
\hline Poorest & 18.1 & 17.6 & 17.7 \\
\hline Poor & 15.5 & 22.2 & 20.7 \\
\hline Average & 16.2 & 24.6 & 22.7 \\
\hline Rich & 21.7 & 23 & 22.7 \\
\hline Richest & 28.5 & 12.6 & 16.2 \\
\hline
\end{tabular}

${ }^{*}$ Ever married: Separated/divorced/widow/widowed.

$\%$, weighted percentage; $n$, number.

likely to consume alcohol (AOR: $1.2,95 \%$ CI: 1.2 to 1.2 ). The women (AOR: 1.7, 95\% CI: 1.6 to 1.7 ), and unemployed (AOR: 7.8, 95\% CI: 7.8 to 7.9 ) were more likely to have inadequate physical activity. The women were more likely to have hypertension (AOR: $1.5,95 \%$ CI: 1.5 to 1.5 ), and obesity (AOR: 2.0, 95\% CI: 2.0 to 2.0 ). The urban population was more likely to have insufficient physical activity (AOR: 1.2, 95\% CI: 1.2 to 1.2), obesity (AOR: 1.5, 95\% CI: 1.5 to 1.5 ), raised blood pressure (AOR: 1.3 , 95\% CI: 1.3 to 1.3 ), diabetes (AOR: $1.6,95 \%$ CI: 1.6 to 1.6) and hyperglycaemia (AOR: $1.1,95 \%$ CI: 1.1 to 1.1 ) (table 4). 
Table 2 Means $(\mathrm{Cl})$ of behavioural, physical and biochemical parameters of the adult population

\section{Means $(\mathrm{Cl})$ of behavioural risk factors of NCD}

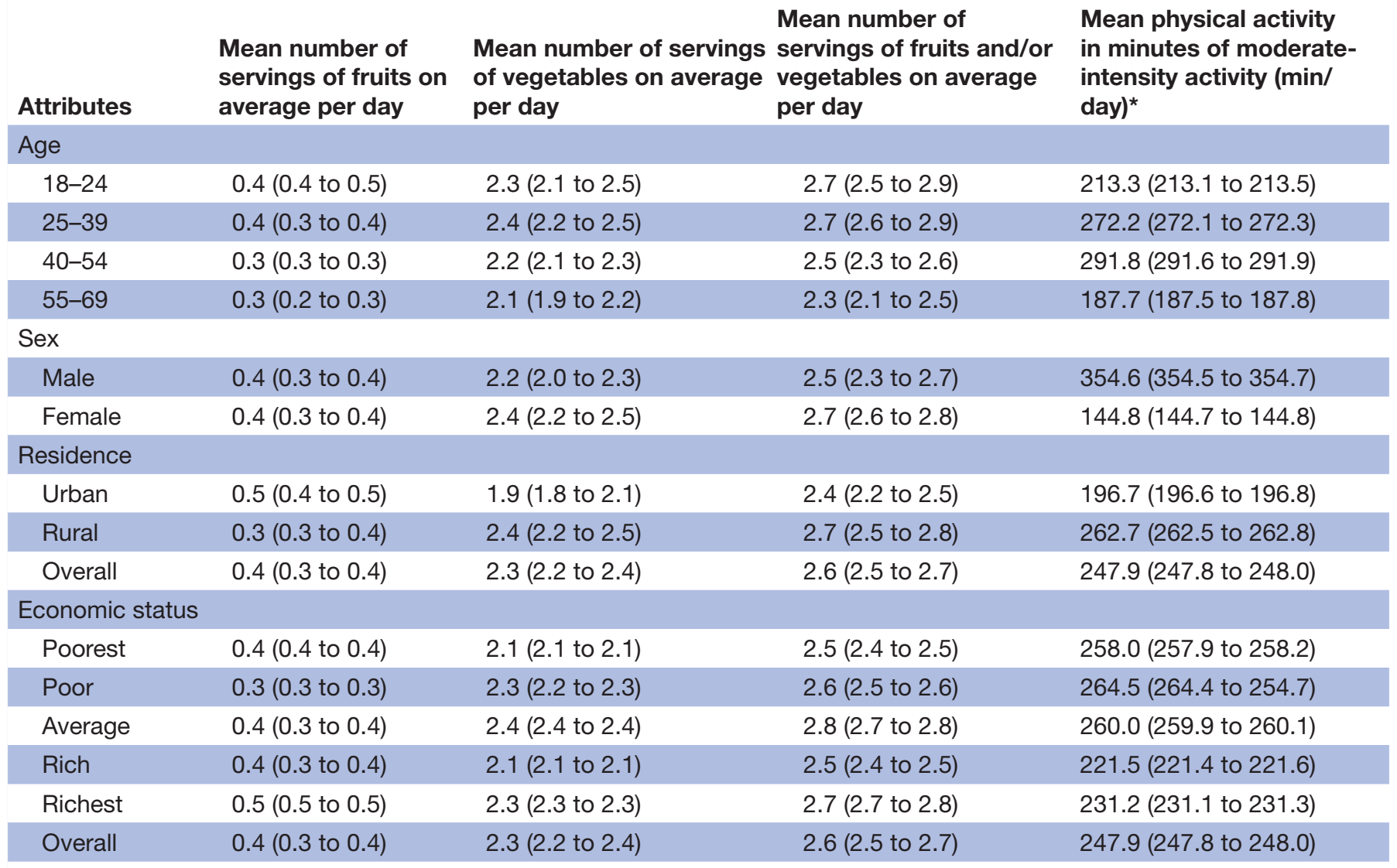

Means (CI) of physical risk factors of NCD

\begin{tabular}{|c|c|c|c|c|}
\hline Attributes & BMI $\left(\mathrm{kg} / \mathrm{m}^{2}\right)$ & WC (cm) & SBP $(\mathrm{mm} \mathrm{Hg})$ & DBP (mm Hg) \\
\hline \multicolumn{5}{|l|}{ Age } \\
\hline $18-24$ & 21.6 (21.3 to 22.0$)$ & 74.5 (73.7 to 75.3$)$ & 113.7 (112.9 to 114.4$)$ & 74.3 (73.7 to 74.9$)$ \\
\hline $40-54$ & 23.0 (22.8 to 23.3) & 80.4 (79.7 to 81.0$)$ & 125.0 (124.2 to 125.8$)$ & $82.2(81.6$ to 82.7$)$ \\
\hline $55-69$ & 22.3 (21.8 to 22.7 ) & 80.4 (79.2 to 81.7$)$ & 130.9 (129.6 to 132.3$)$ & $81.3(80.6$ to 82.1$)$ \\
\hline Male & 21.9 (21.7 to 22.0 ) & 79.1 (78.5 to 79.6$)$ & 121.5 (120.9 to 122.0$)$ & 77.9 (77.5 to 78.3$)$ \\
\hline Female & 23.5 (23.2 to 23.7 ) & 78.2 (77.5 to 78.8$)$ & 120.7 (120.2 to 121.3) & 80.8 (80.5 to 81.2$)$ \\
\hline \multicolumn{5}{|l|}{ Residence } \\
\hline Urban & 23.6 (23.3 to 23.9) & 81.4 (80.7 to 82.1$)$ & 122.6 (122.0 to 123.1$)$ & $80.6(80.2$ to 81.0$)$ \\
\hline Rural & 22.4 (22.2 to 22.6$)$ & 77.8 (77.3 to 78.3$)$ & 119.7 (119.1 to 120.2$)$ & 78.4 (78.0 to 78.8$)$ \\
\hline Poor & 22.5 (22.5 to 22.5$)$ & 78.4 (78.3 to 78.4$)$ & 120.4 (119.5 to 121.2$)$ & 79.1 (78.5 to 79.7$)$ \\
\hline Average & 22.5 (22.4 to 22.5$)$ & 78.0 (78.0 to 78.0$)$ & 120.8 (119.9 to 121.7$)$ & 78.9 (78.3 to 79.5$)$ \\
\hline Rich & 22.6 (22.5 to 22.6$)$ & 78.6 (78.6 to 78.7$)$ & $120.9(120.1$ to 121.7$)$ & 79.3 (78.7 to 79.9$)$ \\
\hline Richest & 23.6 (23.6 to 23.6 ) & $81.6(81.5$ to 81.6$)$ & 123.0 (122.1 to 123.9$)$ & $80.8(80.3$ to 81.4$)$ \\
\hline Overall & 22.7 (22.5 to 22.8 ) & 78.6 (78.2 to 79.1$)$ & $121.1(120.7$ to 121.5$)$ & 79.5 (79.2 to 79.7$)$ \\
\hline
\end{tabular}


Table 2 Continued

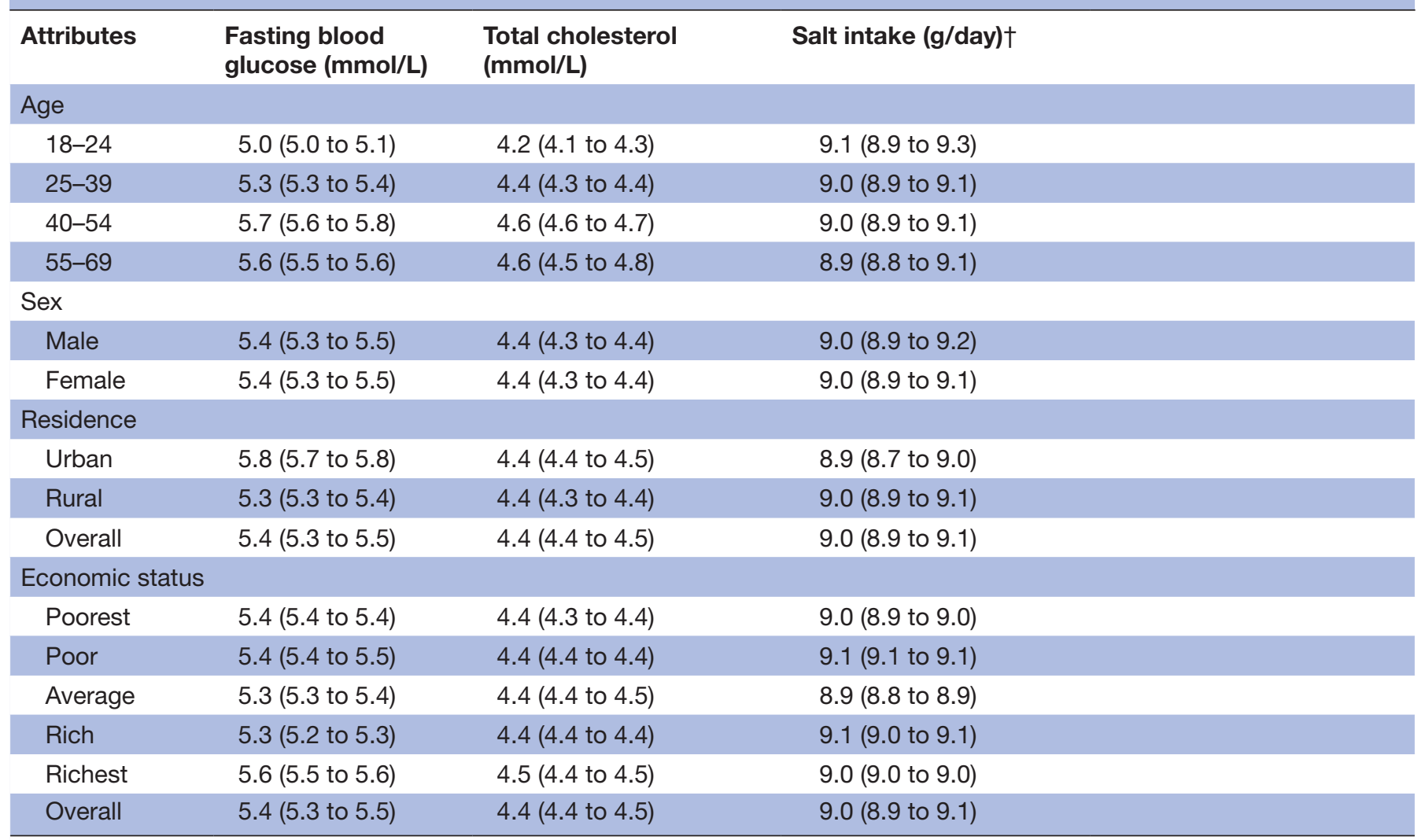

*Minutes spent on vigorous-intensity activities per day are multiplied by 2 , to derive equivalent minutes of moderate-intensity activities and then summed up to obtain the total physical activity in minutes of moderate-intensity activity per day.

†Calculated using 'Tanaka Equation' (based on urinary $\mathrm{Na}+$ concentration).

BMI, body mass index; DBP, diastolic blood pressure; min, minute; NCD, non-communicable diseases; SBP, systolic blood pressure; WC, waist circumference.

Inadequate servings: Intake less than five servings' fruits and/or vegetables on average per day; all of the findings are statistically significant at the $p$ value $<0.05$.

Regarding combined risk factors, $3 \%$ (men $1.9 \%$ and women $4.0 \%$ ) population had no risk factor while $70.9 \%$ had $1 \%$ to $2 \%$ and $26.2 \%$ had $\geq 3 \mathrm{NCD}$ risk factors, which was higher in men $(29.6 \%)$ than in women $(22.8 \%)$ (figure 1).

\section{DISCUSSION}

Based on the analysis of weighted data, this countrywide survey determined the national prevalence of NCD risk factors in three steps including sociodemographic factors; tobacco and salt consumption; fruits and vegetable consumption, and physical activity; overweight and obesity; hypertension; hyperglycaemia; and hypercholesterolaemia. The prevalence of current tobacco consumption was higher than that observed in the Global Adult Tobacco Survey. ${ }^{14}$ It was higher in the rural than the urban population but an average 10\% reduction was observed in both areas compared with STEPS 2010, ${ }^{15}$ which reflects the success of anti-tobacco intervention programmes. The higher prevalence of tobacco uses in the men $(\mathrm{OR}=0.2)$ and elderly imitates the real picture of the South Asia region, ${ }^{16}{ }^{17}$ except Bhutan. ${ }^{18}$

The prevalence of alcohol consumption was much lower in Bangladesh than in India $(1.5 \%$ vs $14.9 \%){ }^{19}$ which could be due to cultural and religious differences. Despite some recall bias, the majority of the population consumed less than five servings of vegetables and fruits per day; though it is more than earlier ${ }^{16}$ but lower than the neighbouring countries. ${ }^{1820}$ Public fear regarding the presence of heavy metals and pesticides in fruits and vegetables $^{2021}$ is not tenuous rather their dietary habit seems to be the driving factor behind it.

The prevalence of insufficient physical activity $(12.3 \%)$ is a glaring pointer towards a growing epidemic of overweight and obesity in our country. Insufficient physical activity was more in urban than in rural population $(14.1 \%$ vs $11.7 \%)$, and in women than in men $(\mathrm{OR}=1.7)$, which is inconsistent with the previous studies in the low- and middle-income countries and South Asian countries. ${ }^{22-24}$ The prevalence of insufficient physical activity has spiked up significantly in comparison with the previous STEPS survey. ${ }^{16}$ Despite a little recall bias, it could be argued that men are involved in more laborious activities than 


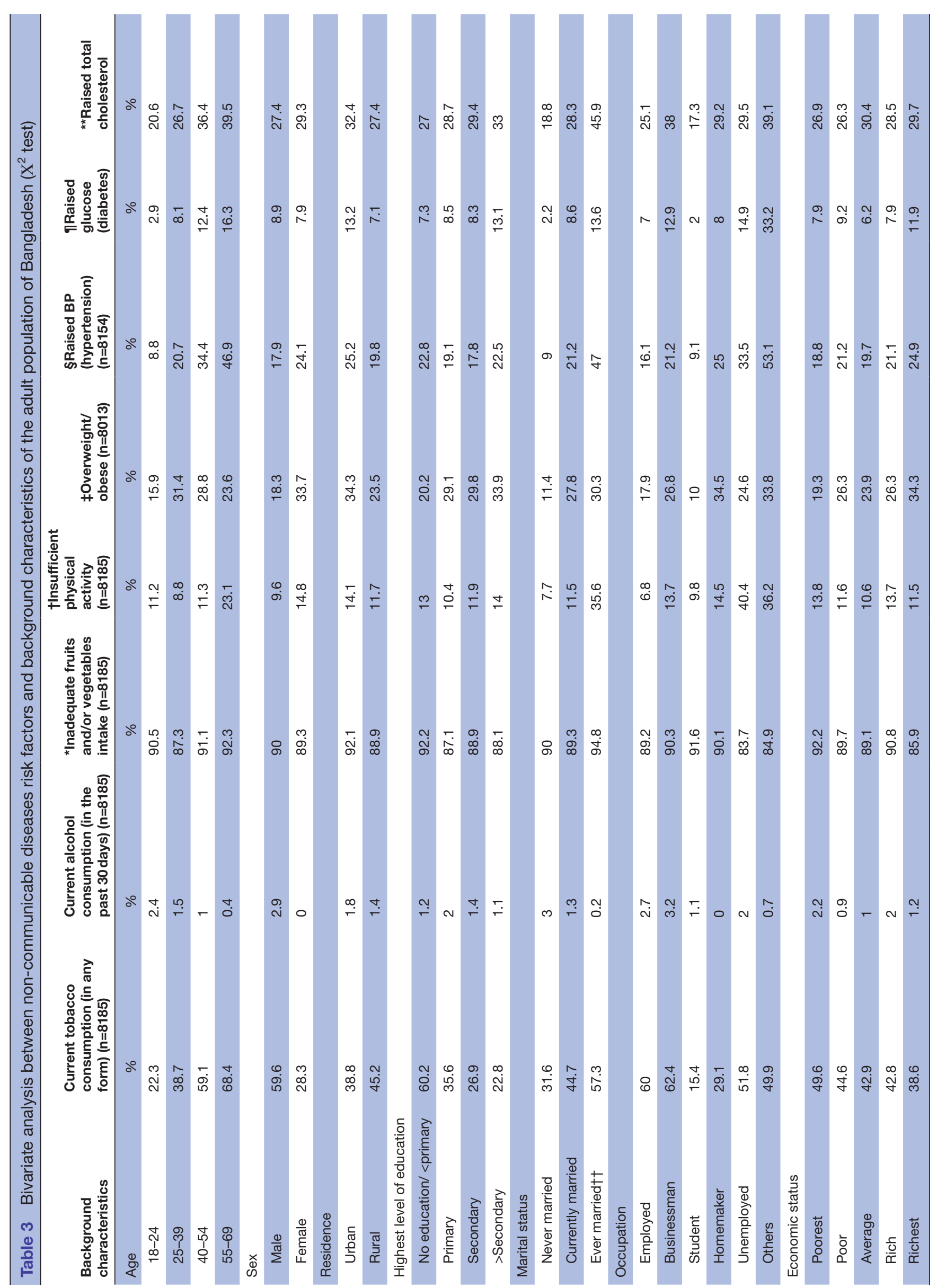




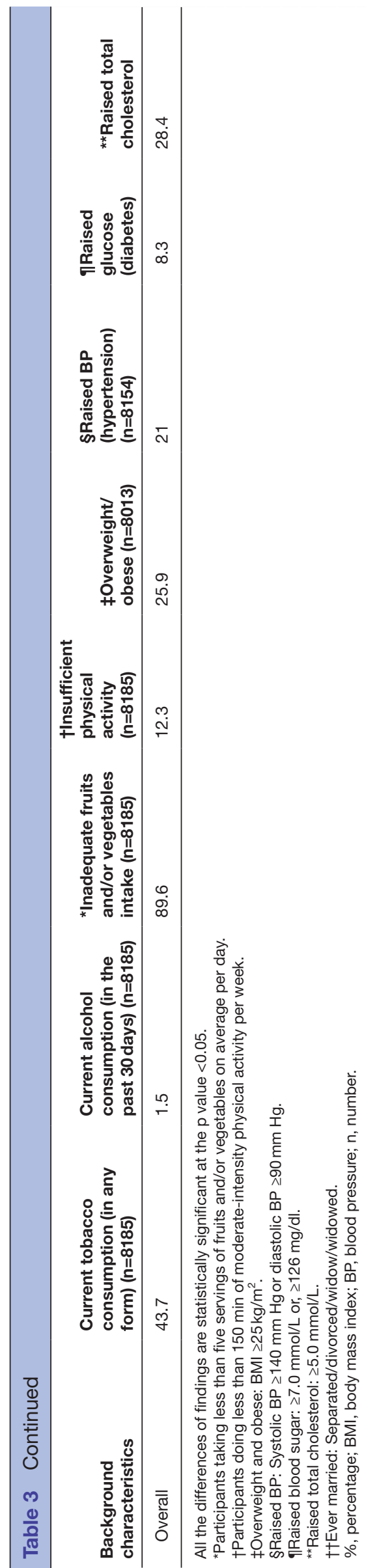

women. High income also excites a sedentary lifestyle like smartphone and computer use. ${ }^{25}$

In comparison with the 2010 survey, the prevalence of overweight and obesity (25.9\%) showed a rising trend with a higher proportion in women than men $(33.7 \%$ vs $18.3 \%) .{ }^{16}$ Shifting towards a sedentary lifestyle in the rural whereas growing health consciousness in the urban population may be the reasons behind it. The prevalence of obesity is comparable to the neighbouring, ${ }^{192627}$ and many developed countries. ${ }^{28}$ About one-fourth of the population had hypertension with significant sex and age differences. The prevalence of hypertension was significantly higher in women ( $\mathrm{AOR}=1.5)$, elderly $(\mathrm{AOR}=9.2)$, urban $(\mathrm{AOR}=1.3)$ and unemployed (AOR=1.8) population. Another population-based study reported the prevalence of hypertension as $12 \%$ to $13 \% .^{29}$ A sedentary lifestyle predisposes hypertension and higher prevalence in women is possibly a bane from the revolutionary success of contraceptive usage among them.

Diabetes mellitus has been steadily creeping into the low- and middle-income countries to reach an epidemic proportion. ${ }^{30}$ The current prevalence $(8.3 \%)$ is a testament to the exponential trend of diabetes as reported in previous systemic reviews. ${ }^{31}{ }^{32}$ With the increasing ages, the prevalence rose steadily and a significant difference was observed in the urban population $(\mathrm{OR}=1.6)$. The effect of unplanned urbanisation, sedentary lifestyle and altered food habits could make the urban population more vulnerable to hypertension. If an effective strategy is not adopted, all these will pose an ominous potential to trigger a range of cardiovascular disease epidemics in the recent future. ${ }^{33}$ Reviews from surrounding countries indicate that dyslipidaemias are slowly increasing in the region. ${ }^{34}{ }^{35}$ About $28.4 \%$ had higher serum cholesterol with a greater propensity in urban than rural population (32.4\% vs $27.4 \%)$.

The current study found $3 \%$ had no, $70.9 \%$ had 1 to 2 and $26.2 \%$ had $\geq 3 \mathrm{NCD}$ risk factors while the previous STEPS survey 2010 found $1.3 \%, 77.4 \%$ and $28.3 \% .^{16}$ These discrepancies could be due to the positive impacts of comprehensive NCD prevention and control activities in the country. In 2018, $\geq 3$ risk factors were higher in women than in men $(31.5 \%$ vs $21.7 \%)$ while it was reversed in 2010 (22.8\% vs $29.6 \%$ ). This finding suggests an emphasised NCD risk factors alleviation programme for the women.

Despite few methodological limitations like recall bias with self-reported behavioural data of the participants, challenges of transportation of biological samples maintaining the cold chain, and the inability of the crosssectional design to infer causal relationships among the risk factors, the study unveiled crucial nationally representative data on NCD risk factors.

Raising public awareness through health education seems to be a vital viable option for modifying the mass dietary habit and tobacco consumption behaviour of the people. Bangladesh can adopt several strategies like healthy urban community design making neighbourhoods 


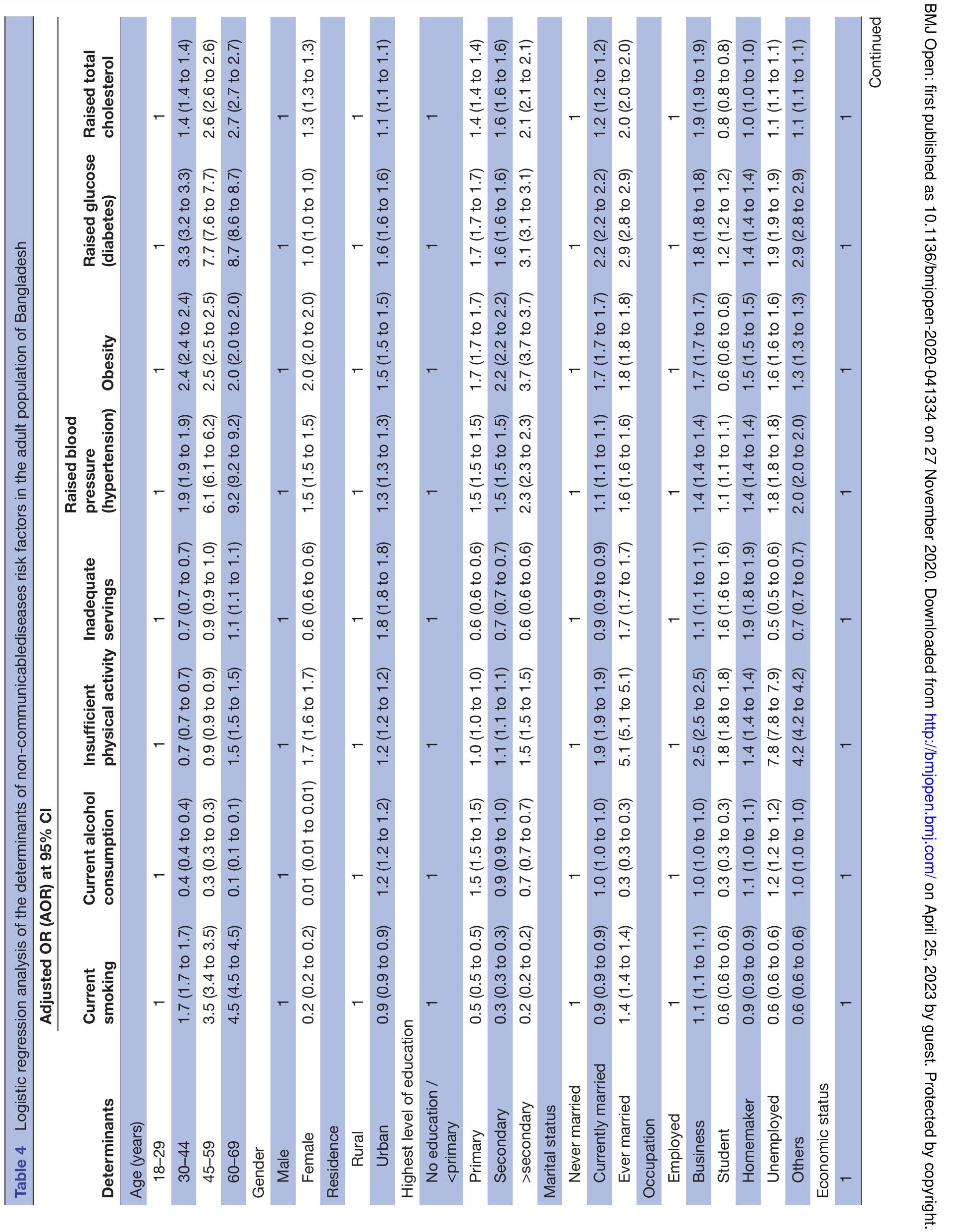



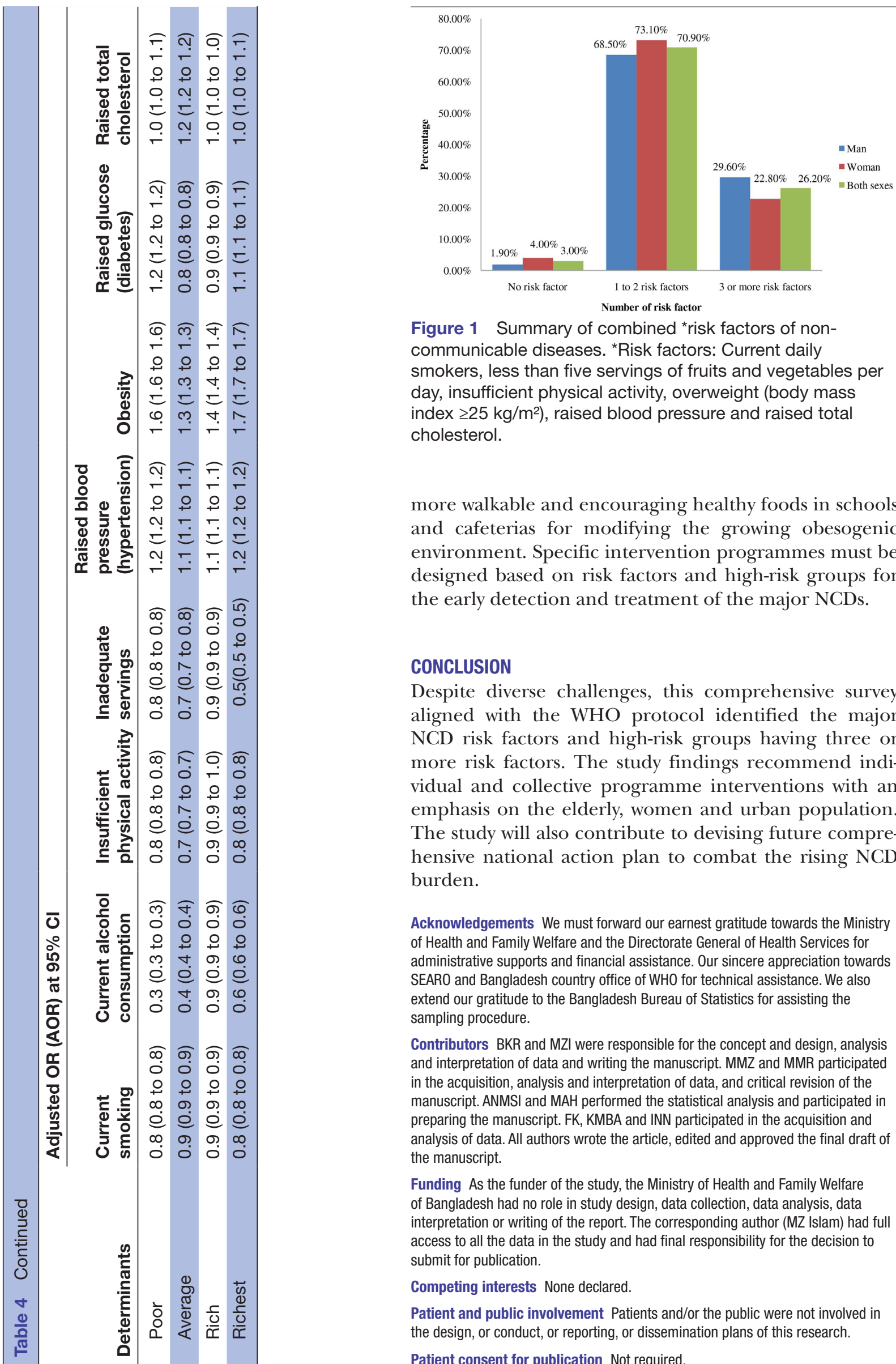

Figure 1 Summary of combined *risk factors of noncommunicable diseases. *Risk factors: Current daily smokers, less than five servings of fruits and vegetables per day, insufficient physical activity, overweight (body mass index $\geq 25 \mathrm{~kg} / \mathrm{m}^{2}$ ), raised blood pressure and raised total cholesterol.

more walkable and encouraging healthy foods in schools and cafeterias for modifying the growing obesogenic environment. Specific intervention programmes must be designed based on risk factors and high-risk groups for the early detection and treatment of the major NCDs.

\section{CONCLUSION}

Despite diverse challenges, this comprehensive survey aligned with the WHO protocol identified the major NCD risk factors and high-risk groups having three or more risk factors. The study findings recommend individual and collective programme interventions with an emphasis on the elderly, women and urban population. The study will also contribute to devising future comprehensive national action plan to combat the rising NCD burden.

Acknowledgements We must forward our earnest gratitude towards the Ministry of Health and Family Welfare and the Directorate General of Health Services for administrative supports and financial assistance. Our sincere appreciation towards SEARO and Bangladesh country office of WHO for technical assistance. We also extend our gratitude to the Bangladesh Bureau of Statistics for assisting the sampling procedure.

Contributors BKR and MZI were responsible for the concept and design, analysis and interpretation of data and writing the manuscript. MMZ and MMR participated in the acquisition, analysis and interpretation of data, and critical revision of the manuscript. ANMSI and MAH performed the statistical analysis and participated in preparing the manuscript. FK, KMBA and INN participated in the acquisition and analysis of data. All authors wrote the article, edited and approved the final draft of the manuscript.

Funding As the funder of the study, the Ministry of Health and Family Welfare of Bangladesh had no role in study design, data collection, data analysis, data interpretation or writing of the report. The corresponding author (MZ Islam) had full access to all the data in the study and had final responsibility for the decision to submit for publication

Competing interests None declared.

Patient and public involvement Patients and/or the public were not involved in the design, or conduct, or reporting, or dissemination plans of this research.

Patient consent for publication Not required. 
Ethics approval We obtained the ethical approval of the National Research Ethics Committee (NREC) of Bangladesh.

Provenance and peer review Not commissioned; externally peer reviewed.

Data availability statement Data are available in a public, open access repository. Extra data can be accessed via the Dryad data repository at http://datadryad.org/ with the doi:10.5061/dryad.zkh18937f.

Open access This is an open access article distributed in accordance with the Creative Commons Attribution Non Commercial (CC BY-NC 4.0) license, which permits others to distribute, remix, adapt, build upon this work non-commercially, and license their derivative works on different terms, provided the original work is properly cited, appropriate credit is given, any changes made indicated, and the use is non-commercial. See: http://creativecommons.org/licenses/by-nc/4.0/.

\section{ORCID iDs}

Md Ziaul Islam http://orcid.org/0000-0002-5582-2402

M M Zaman http://orcid.org/0000-0002-1736-1342

\section{REFERENCES}

1 WHO. Global health estimates: deaths by cause, age, sex and country, 2000-2012. Geneva: World Health Organization, 2014.

2 WHO. Projections of mortality and causes of death, 2015 and 2030. Health statistics and information systems. Available: http://www.who. int/healthinfo/global_burden_disease/projections/en/

3 WHO. Non communicable diseases progress monitor, 2017. Available: http://apps.who.int/iris/bitstream/handle/10665/258940/ 9789241513029eng.pdf;jsessionid=9

4 WHO. Global status report on non-communicable diseases, 2014. Available: http://apps.who.int/iris/bitstream/handle/10665/148114/ 9789241564854_eng.pdf?sequence-1

5 WHO. Surveillance of chronic diseases: risk factors: country-level data and comparable estimates (surf reports 2): Bangladesh, 2005. Available: http://www.who.int/infobase/surf2/ html_files/SEARO/ Bangladesh.pdf

6 Wagner K-H, Brath $\mathrm{H}$. A global view on the development of non communicable diseases. Prev Med 2012;54:S38-41.

7 Zaman MM, Bhuiyan MR, Karim MN, et al. Clustering of noncommunicable diseases risk factors in Bangladeshi adults: an analysis of steps survey 2013. BMC Public Health 2015;15:659.

8 Mahta $\mathrm{H}$. Prevalence of diabetes, coronary heart disease and the risk factors attributed to these disorders in the urban population of Bangladesh. SEARO, 2008. Available: http://www.who.int/infobase/ surf2/ html_files/SEARO/Bangladesh.pdf

9 WHO. Burden of non-communicable diseases. WHO Bulletin, 2016.

10 WHO. 65th World health assembly, 2012.

11 Islam N, Islam MN, Khanam K. Smoking habit among Bangladesh Secretariat staff. Bangladesh Med Res Counc Bull 1990;16:62-9.

12 WHO. Global adult tobacco survey (GATS) Bangladesh, 2009. Available: https://www.who.int/tobacco/surveillance/fact_sheet_of_ gats_bangladesh_2009.pdf

13 WHO. 66th World health assembly, 2013.

14 Bangladesh Bureau of Statistics (BBS). Global adult tobacco survey (GATS) Bangladesh, 2017.

15 Directorate General of Health Services (DGHS), Ministry of Health and Family Welfare. Non-communicable disease risk factor survey in Bangladesh 2010. World Health organization - country office for Bangladesh, 2011. Available: http://www.searo.who.int/entity/ noncommunicable_diseases/data/Bangladesh_2010_STEPS_ Survey_Report.pdf
16 Palipudi K, Rizwan SA, Sinha DN, et al. Prevalence and sociodemographic determinants of tobacco use in four countries of the world Health organization: south-east Asia region: findings from the global adult tobacco survey. Indian J Cancer 2014;51:S24-32.

17 Aryal KK, Mehata S, Neupane S, et al. The burden and determinants of non communicable diseases risk factors in Nepal: findings from a nationwide steps survey. PLoS One 2015;10:e0134834.

18 Gurung MS, Pelzom D, Dorji T, et al. Current tobacco use and its associated factors among adults in a country with comprehensive ban on tobacco: findings from the nationally representative STEPS survey, Bhutan, 2014. Popul Health Metr 2016;14:1-9.

19 Thakur JS, Jeet G, Pal A, et al. Profile of risk factors for noncommunicable diseases in Punjab, Northern India: results of a statewide steps survey. PLoS One 2016;11:e0157705.

20 Shaheen N, Irfan NM, Khan IN, et al. Presence of heavy metals in fruits and vegetables: health risk implications in Bangladesh. Chemosphere 2016;152:431-8.

21 Alamgir Zaman Chowdhury M, Fakhruddin ANM, Nazrul Islam $\mathrm{M}$, et al. Detection of the residues of nineteen pesticides in fresh vegetable samples using gas chromatography-mass spectrometry. Food Control 2013;34:457-65.

22 Pengpid S, Peltzer K, Kassean HK, et al. Physical inactivity and associated factors among university students in 23 low-, middle- and high-income countries. Int J Public Health 2015;60:539-49.

23 Haase A, Steptoe A, Sallis JF, et al. Leisure-Time physical activity in university students from 23 countries: associations with health beliefs, risk awareness, and national economic development. Prev Med 2004;39:182-90.

24 Yahia N, Wang D, Rapley M, et al. Assessment of weight status, dietary habits and beliefs, physical activity, and nutritional knowledge among university students. Perspect Public Health 2016;136:231-44.

25 Konharn K, Santos MP, Ribeiro JC. Socioeconomic status and objectively measured physical activity in Thai adolescents. J Phys Act Health 2014;11:712-20.

26 Bhagyalaxmi A, Atul T, Shikha J. Prevalence of risk factors of noncommunicable diseases in a district of Gujarat, India. J Health Popul Nutr 2013;31:78.

27 Jayawardena R, Byrne NM, Soares MJ, et al. Prevalence, trends and associated socio-economic factors of obesity in South Asia. Obes Facts 2013;6:405-14.

28 WHO. Global status report on non-communicable diseases. Geneva: World Health Organisation, 2014.

29 Zaman MM, Yoshiike N, Rouf MA, et al. Cardiovascular risk factors: distribution and prevalence in a rural population of Bangladesh. $J$ Cardiovasc Risk 2001;8:103-8.

30 Akter S, Rahman MM, Abe SK, et al. Prevalence of diabetes and prediabetes and their risk factors among Bangladeshi adults: a nationwide survey. Bull World Health Organ 2014;92:204-13.

31 Biswas T, Islam A, Rawal LB, et al. Increasing prevalence of diabetes in Bangladesh: a scoping review. Public Health 2016;138:4-11.

32 Saquib N, Saquib J, Ahmed T, et al. Cardiovascular diseases and type 2 diabetes in Bangladesh: a systematic review and metaanalysis of studies between 1995 and 2010. BMC Public Health 2012;12:434.

33 Emerging Risk Factors Collaboration, Sarwar N, Gao P, et al. Diabetes mellitus, fasting blood glucose concentration, and risk of vascular disease: a collaborative meta-analysis of 102 prospective studies. Lancet 2010;375:2215-22.

34 Gupta R, Guptha S, Sharma KK, et al. Regional variations in cardiovascular risk factors in India: India heart Watch. World J Cardiol 2012;4:112.

35 Jafar TH, Haaland BA, Rahman A, et al. Non-communicable diseases and injuries in Pakistan: strategic priorities. Lancet 2013;381:2281-90. 